\title{
Peripheral artery disease: one-year single-centre overview
}

\author{
Ljiljana Banfić, \\ Jasmina Hranjac, \\ Majda Vrkić Kirhmajer, \\ Zoran Miovski*, \\ Dražen Perkov, \\ Savko Dobrota, \\ Ana Marija Alduk, \\ Ranko Smiljanić
}

University of Zagreb School of Medicine, University Hospital Centre Zagreb, Zagreb,

Croatia
KEYWORDS: peripheral vascular diseases, percutaneous transluminal angioplasty.

CITATION: Cardiol Croat. 2017;12(9-10):382. | https://doi.org/10.15836/ccar2017.382

*ADDRESS FOR CORRESPONDENCE: Zoran Miovski, Klinički bolnički centar Zagreb, Kišpatićeva 12, HR-10000 Zagreb, Croatia. / Phone: +385-98-464-811 / E-mail: miovski.zoran@gmail.com

ORCID: Ljiljana Banfić http://orcid.org/0000-0002-4538-8980 • Jasmina Hranjec http://orcid.org/0000-0001-8356-7376 Majda Vrkić Kirhmajer http://orcid.org/0000-0002-1340-1917 • Zoran Miovski http://orcid.org/0000-0002-3850-8905 Dražen Perkov http://orcid.org/0000-0001-5398-059X • Savko Dobrota http://orcid.org/0000-0003-0785-5143 Ana Marija Alduk http://orcid.org/0000-0002-5438-4439 • Ranko Smiljanić http://orcid.org/0000-0003-3230-049X

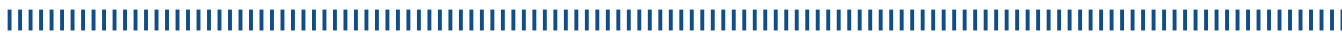

This overview is related to one year diagnostic, treatment and follow up in patient with intermittent claudication. The patients presented with intermittent claudication were selected for investigation according to the clinical data, comorbidities, functional screening testing (pletismography, segmental pressures and ABI), arterial duplex scanning and finally submitted to CT angiography that could discriminate candidates for the best treatment options; angiointerventional or vascular surgery treatment. ${ }^{1}$ In the group of 480 patient evaluated in one year period 119 were eligible for angiointerventional or surgical procedure according to the functional testing (pletismography and ABI, arterial duplex scanning) and 114 of them were referred to CT angiography. The patients evaluated on functional data $\mathrm{ABI}$ and pletismography before and after the treatment in the 48 hours period (100\%), 3 months after (40 $\%$ ) and six months (14.9\%) follow up time interval. The majority of patients were treated by angiointerventional techniques (71 patient, $62 \%), 17$ patients (14\%) with optimal medical treatment and, 16 (14\%) as elective surgical candidates, and the rest as urgent surgical patients as 3 of them required amputation because of life threatening critical limb ischemia. According to the data $50 \%$ of the patients treated with percutaneous transluminal angioplasty (PTA) were treated with drug eluting balloons or balloons only, while the rest PTA was done with stents. Early results were determined 48 hours after the procedure and $85 \%$ had successful outcomes according to the angiography, ABI and pletismography data. $10 \%$ of patients had some complications such as 1 retroperitoneal hematoma that needed surgical interventions, 6 minor local dissections, 4 minor hematomas, and no fatal event. In conclusion: Patient candidates were selected on functional testing and CT angiography thereafter, as resulted in proper patient selection that generate successful early interventional results. We cannot assume long term 6 months results because of low number of patients submitted for follow up evaluation.
RECEIVED:

September 24, 2017

ACCEPTED:

September 26, 2017

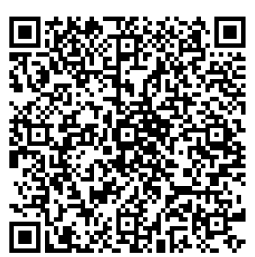

LITERATURE IIIIIIIIIIIIIIIIIIIIIIIIIIIIIIIIIIIIIIIIIIIIIIIIIIIIIIIIIIIIIIIIIIIIIIIIIIIIIIIIIIIIIIIIIIIIIIIIIIIII

1. Aboyans V, Ricco JB, Bartelink MEL, Björck M, Brodmann M, Cohnert T, et al. 2017 ESC Guidelines on the Diagnosis and Treatment of Peripheral Arterial Diseases, in collaboration with the European Society for Vascular Surgery (ESVS): Document covering atherosclerotic disease of extracranial carotid and vertebral, mesenteric, renal, upper and lower extremity arteries; Endorsed by: the European Stroke Organization (ESO); The Task Force for the Diagnosis and Treatment of Peripheral Arterial Diseases of the European Society of Cardiology (ESC) and of the European Society for Vascular Surgery (ESVS). Eur Heart J. 2017 Aug 26. https://doi.org/10.1093/eurheartj/ehx095 